\title{
On Key Points of Financial Cost Management in Small and
}

\section{Medium-Sized Enterprises}

\author{
Xingwu Yu \& Weixing Wang \\ College of Economics and Management, Changzhou University \\ Changzhou 213164, Jiangsu, China \\ E-mail: dzyxw@163.com
}

The research is supported by the College Philosophy Social Science Fund of Jiangsu Province Office of Education (No. 09SJD630022) and the Soft Science Research Project of Changzhou City (No. CR20099009). (Sponsoring information)

\begin{abstract}
Chinese small and medium-sized enterprises (SME), accounting for $99.3 \%$ of all Chinese corporations, create enormous economic fortune and employment opportunity. However, most of SMEs are lack of capital, with simple equipments and improper management, so they are incapable to withstand risks and easy to be involved in difficulty. Therefore, we should properly guide SMEs to enhance financing, investment management and the management of other value chain activities, which will contribute to their survival, development, strength, and increasing improvement of market competitiveness.
\end{abstract}

Keywords: Small and Medium-Sized Enterprises, Financial Cost Management, Risks, Prevention

Along with continuous development and consummation of Chinese market economy, plenty of various small and medium-size enterprises (SME) have emerged rapidly, becoming the most active and potential organizations in Chinese economy. According to the statistic data of 2008, SMEs, accounting for $99.3 \%$ of all Chinese corporations, create $60 \%$ of GDP, $50 \%$ of tax revenue, over $75 \%$ of city employment, $65 \%$ of patent, $75 \%$ of technological innovation, over $80 \%$ of new-product launch and $68 \%$ of exportation. However, in recent years, the price of raw materials goes up, labor cost rises and international financial crisis comes up, which results in nearly half of SMEs' bordering on closing down. Confronting the pressure from current higher cost, only by improving financial cost management, SMEs can overcome difficulty and fulfill sustainable and healthy development. The purpose of this paper is to study SME's financial cost management on financing, investment, production and operation. We shall propose some theoretical guidance for SMEs on their survival, development and promotion of international competitiveness.

\section{Select Financing Modes and Prevent Financial Risks}

Both establishment and operation of SMEs need capital, so financing is the primary problem for their survival and development. Firstly, we shall use experience-judgment method, investigation-research method, and other qualitative forecast methods, or regression line method; revenue/capital forecast method, pro forma balance sheet method and other quantitative forecast methods, to figure out the capital demand of SMEs, then select financing channels and modes. Proper selection of financing channels and modes is significant for SMEs to survive, develop and resist financial risks.

\subsection{Types of Financing Modes}

\subsubsection{Shareholders' Investment}

Shareholders' investment is also called stock equity capital or stock equity fund, which is the important capital source that SMEs can hold for long term and dominate independently. When SMEs are established, their minimum equity capital, shareholders' investment modes and term should be in accordance with China's "Law of Corporation" and other relevant regulations. When SMEs enlarge operational scale or field, they can further shareholders' investment or increase capital by reserving profits to raise equity capital in order to meet capital demand. The characteristics of equity capital are permanent occupation, no return and satisfying SMEs' minimum demand for capital; stock interest depending on SMEs' operational situation; comparative low financial risks. Equity capital is also the foundation and condition of raising a loan. With the guarantee of equity capital, SMEs could be capable of raising a loan. Shenzhen Security Exchange has established SME Board and 
Second Board, which provide those SMEs with market entry qualification with good financing platform. They can raise plenty of equity capital by being listed.

\subsubsection{Borrow Capital}

Borrowed capital or debt capital refers to the capital raised by credit loan, mortgage loan, hock, and financing lease through banking, non-banking financial organizations and other nongovernmental channels. So SMEs are required to have good business credit, and provide with guarantees or guarantors. Simultaneously, there are some restrictions on drawing or using the capital, so financing amount is limited. Borrowing capital is a fast financing mode with fixed interest deducted before tax, and the cost of capital is quite low. But SMEs have to repay principal and interest on time according to related contracts. So this kind of capital, with high financial risk, has comparatively high requirements on future cash payable capability to SMEs. Short-term loan within one year mainly meets the flow capital demand of SMEs, and long-term loan is mostly used to set up fixed assets and meet the demand for long-term flow capital. When the market value created by loan exceeds its cost, shareholder's income will rise and the value of SMEs will be promoted as well.

\subsection{Prevent Financial Risks}

The broad sense of financial risks refers to all kinds of risks aroused by financing, capital using, income distribution and other financing activities. The narrow sense of financial risks means corporations can't repay principal and interest on time, which lowers earnings per share, due to using financial leverage. The cost of equity capital is high, but with low financial risk, while that of loan is low, but with high financial risk. The ratio of loan and equity is called equity ratio. Usually it is better if the ratio is below one. Meanwhile, equity capital and long-term loan should be enough for purchasing long-term assets. The long-term loan can not be over the operational capital, otherwise enterprises will face high financial risks. Whether financial risks be eliminated mainly depends on whether enterprises repay principal and interest on time, again which depends on operational achievements, i.e. well accomplishing income and complementing charges, and simultaneously, depends on the conformity between current income and future principal and interest. They have to ensure capital profit margin before interest and tax is bigger than debt interest rate to raise earnings per share and make shareholders obtain benefit from financial leverage. Existing operational risks will enlarge financial risks, so the control on financial risks can't be separated from the estimation and control on operational risks. SMEs can promote payoff ability by proper operation and effective management to achieve high profit margin before interest and tax and sufficient cash, so as to strengthen repaying ability and lower financial risks.

\section{Select Investment Mode and Prevent Investment Risks}

After SMEs obtain some capital, they will start many kinds of investment activities, such as setting up workshop, purchasing machines and equipments or oversea stock investment. When SMEs make investment decision, they need to consider domestic and international macro-economic development tendency and their own operational strategy, as well as their capital situation. They also should combine their own advantages and disadvantages, and confronting opportunities and threats, make feasibility demonstration based on forecast of market selling prospect, of needed production resource and of future operation. Besides traditional investment index analysis, they also need to make a great deal of qualitative analysis during demonstration process, such as value chain analysis, cost drivers analysis, competitive advantages analysis and so on, in order to study the important influence of various non-currency measurement factors on investment projects. When making investment decision, they should attach importance on both quantitative factors and qualitative factors, on both currency measurement and non-currency measurement, and on combination of quantitative calculation and systematic judgment. SMEs can select the following several investment modes.

\subsection{Select Establishment Mode and Prevent Risks}

\subsubsection{Establish SMEs by Whole Purchasing Other Enterprises}

Current Chinese market economy is on a developing stage to be consummated, so the market is not mature yet. Most private enterprises are small in size and low in technology and management level. Some enterprises can't withstand keen market competition to sell products, and at the same time many losing local enterprises are looking for buyers. As for the entrepreneurs or investors with capital, management experiences or technological advantages, it is an ideal investment opportunity. It can lower entry cost, rapid obtaining new operational resources and exploiting new market by whole purchasing other enterprises to establish SMEs. By whole purchase investors can get land resource, workshop and equipments, and even management staff, technological persons, buying channels, selling network and so on. All these tangible and intangible resources will benefit optimizing resource distribution in short term for investors and achieving comparatively high investment return. 
This kind of investment mode has become significant for China to develop economy, adjust economic structure, and reuse assets stock.

\subsubsection{Self-Establish SMEs by Purchasing Various Assets}

On self-establishing SMEs, they need to purchase land, construct workshop, purchase equipments, and then establish buying channels, exploit selling market and equip a variety of staff. Based on confirmed industry or field, they should make extractive decision and systematic layout. Thereinto, the location of an enterprise is very essential, as it is related not only to purchase, but also to the exploitation of selling market. Simultaneously, it is also concerned with recruitment, labor cost, and local policy. Reasonable location and environment may contribute to obtaining support from local policy, and lowering land cost and other investment cost as well. It benefits long-term development of SMEs, withstanding investment risks and long-term investment earnings. Moreover, purchase of workshop and equipments needs enormous capital, which can be solved by renting or buying cheep but usable old houses and equipments. These above two methods are quite common among SMEs and help to lower investment risks. SMEs need management and technological support. If investors have abundant managerial experiences and skillful professional technology, and participate management themselves, the problem could be solved easily. Otherwise, they should actively recruit management staff and technological staff so as to improve management level, raise investment earnings and prevent investment risks.

\subsection{Select Investment Mode and Prevent Risks during Continuous Operation Term}

After several-years operation SMEs have gained some earnings and accumulated some capital, so they take every opportunity to invest. They can implement scale operation by enlarging production scale or diversified operation by enlarging operation field. Also they may directly invest to other enterprises or buy securities to invest. The same as establishing SMEs, the investment project during continuous operation term also should be based on market forecast, information collection and analysis, and estimation measurement, and scientifically demonstrated on technological feasibility and economic efficiency. Subsequently, investors make a decision on that. Well-running SMEs could form decision teams, consisting of top management staff, technological persons and law \& policy consultants, for the purpose of feasibility research. They may consign professional investment consultation companies for feasibility demonstration to ensure investment decisions are right and scientific, which is beneficial to higher investment returns and avoids big risks from faulty investment decisions.

On investing during continuous operation term, SMEs should notice the relationship between present benefits and long-term benefits, carefully make operational development strategy, and cautiously select investment modes. They also need to pay attention to matching and coordination between new investment and previous business on technology, operation, market and management, in order to lower investment cost, producing cost and organizational management cost, and consequently strengthen earning ability of investment projects to withstand various risks better.

\section{Strengthen Daily Financial Cost Management and Operational Risks Prevention}

After established, SMEs should properly arrange material purchase, staff equipment, technology equipment, production and marketing, guided by set overall strategy, and well construct particular value chain. During construction process, they should try to optimize and coordinate every subject activity and supporting activity of value chain, focusing on the scientificity and feasibility of every managerial activity. They are supposed to fulfill the diversification or cost advantage of products, promote market share and competitiveness, achieve competitive advantage, obtain stable and increased annual profit and prevent operational risks better, through strengthening financial cost management on material purchase, production, transportation, marketing and service after sale. SMEs should strengthen financial cost management in the following aspects.

\subsection{Strengthen $R \& D$ Innovation Management}

$\mathrm{R} \& \mathrm{D}$ innovation is the important guarantee of keeping SMEs' continuous survival and development and the important activity of withstanding operational risks. Many SMEs start from learning and imitation, and gradually develop through capital accumulation for many years. So their R\&D innovation capability is still on quite low level compared to big enterprises, without any equal competition. Meanwhile, plenty of SMEs take price competition strategy, which easily arouses excessive competition and loss of earning space, resulting in waste of resources and lower efficiency. Thus, SMEs must strengthen independent innovation consciousness, enlarge $\mathrm{R} \& \mathrm{D}$ innovation investment, break leading key technique, exploit new products and services, take non-price competitive strategy, and establish core competitiveness. Michael Porter claimed in "Competitive Advantages", "Technology innovation is the foundation of forming competitive advantages". Scientific technology can not only improve product quality, but also increase productive efficiency, save materialized labor and live labor cost, 
and form competitive advantages. "Smiling curve" theory tells us, R\&D innovation has one of the most added values among the whole industrial chain. Enterprises can enhance product earning ability by R\&D innovation, and then strengthen management efficiency and internal coordination effect by systematic innovation and cultural innovation, so as to reduce management cost and promote overall benefits for better withstanding operational risks. There are many sorts of modes for enterprises to develop R\&D activities, such as self R\&D, associated R\&D with other enterprises of the industry, and cooperation R\&D with research institutions.

\subsection{Strengthen Human Resource Management}

Human Resource (HR) takes up primary position among all resource factors of SMEs. It is the most needed resource of SMEs and needs capital investment surly. Under current market economy situation, the key point of competition among enterprises is the competition for talented persons. To great extent, success or failure in the competition depends on exploitation and utilization of HR. the core of modern enterprise management is the management on human. HR management is to properly and effectively select, use, appraise and train required staff, to ensure enterprises' normal running and fulfill set target. HR management must involve cost-benefit analysis, which should be on how to invest capital in HR development and utilization and on preventing HR investment risk; so that the limited capital can be used in the most needed place. Firstly, SMEs may retain several wise and managerial experts as decision brainmen of investors. They could participate decision process and propose constructive suggestions on decision making, which results in higher scientificity of decision. Secondly, SMEs can design reasonable salary plan and introduce professional managers who are good at operation and management of the industry. Furthermore, they may form a professional management team on a high level to be responsible for implementation of decisions and fulfillment of all operational management work, so as to improve the efficiency of management. Thirdly, they need to arrange some capital for retaining imperative professional technology consultants and other these persons for training, to raise the specialization level of all kinds of technicians entirely and provide the production and operation of SMEs with good technical guarantee. Finally, we should consummate the stimulating system of SMEs, inspiring and mobilizing staff to develop their working skills. We need to lead them to integrate individual targets into a whole target and commit themselves to corporate target, so that the capability of earning and of withstanding risks could be enhanced.

\subsection{Strengthen Material Purchase Management}

Under the requirements of strategic target and layout of SMEs, they should firstly purchase materials needed for production and operation. Material purchase is extremely important in SMEs' daily operation, which determines whether production and operation can develop normally, whether the quality and cost advantage of products can be achieved, and the investment effects of SMEs as well. Therefore, SMEs should study the reliability, economy and rationality of material purchase, and then choose suppliers and transportation routes. Reliability means material supply should be in time and sufficient, which is the premise of normal production and operation. Economy means whether and how much profit will be achieved after materials are put into production. The quality and price of materials have to be considered, as well as fare, loading and unloading fee, other purchase fee, and technical requirements. Thus, SMEs must deeply analyze and study economic benefits according to material supply and demand situation. Rationality means whether utilization of material is sufficient and whether utilization of resources is systematic. Due to limitation of resources, enterprises should avoid wasting and improper using resources, but develop green business and consciously obey governmental policies and regulations. SMEs need to establish decision system of material purchase and healthy internal control system of that. Through reasonable matching between value chain of SMEs and that of suppliers, the information of reorder and economic order could be transferred in time, material supply in time and capital occupation control could be guaranteed, normal business operation could be ensured, and operational risks could be lowered as well.

\subsection{Strengthen Production Management}

Production refers to the whole process from material to final manufactured product, including key subject activities of manufacture, which becomes an essential cost center of SMEs. Facing increasing keen market competition, customers become more and more selective to plenty of suppliers, which results in more and more complex customer groups for SMEs. Therefore, SMEs should choose their own business field; systematically consider price, performance and quality of products, and what target customers require on them, according to corporate target, so as to establish survival space of products, that is to say, producing products with proper performance and quality at right price. SMEs should establish a set of systematic management system of quality, performance and cost, in order to quickly react to any change of customer groups. From the perspective of technical maturity and product lifecycle, they can use cost driver analysis to discuss the potential of cutting cost, study corresponding countermeasure and implement in time. During production process, they should enhance 
budget management, responsibility cost management and overall quality management, effectively use present productivity, reasonably organize production process, and try to lower cost on condition of ensuring performance and quality of products, for the purpose of remaining and promoting competitive advantages. They also need to develop new products in accordance with the changeable tendency of customers' requirements. They could apply target cost method and value engineering method to make sure of target cost of new products and approaches of reaching target cost, and then strengthen cost management on new products in case of lack of products' successor and uncontrol of cost.

\subsection{Strengthen Marketing Management}

On the basis of present economic resources, market demand and market share of competitors, SMEs should select target market segmentation and determine survival space of products. SMEs should pay more attention to changes of market demand and of enterprises' market position, and then adjust or develop new combination of products and services in time. They also need to enhance original market, exploit and occupy new target market through appropriate price strategy, distribution strategy and selling strategy. Firstly, SMEs should strengthen innovation of marketing value, establish values of brand marketing, green marketing and ecological marketing, to adapt external environment better and promote healthy development and stronger competition. Secondly, they should strengthen innovation of marketing organization and marketing skill, establish flat and efficient marketing organizations, actively develop network marketing and E-commerce, utilize alliance business, chain business, logistic distribution, and other modern distribution methods, strengthen customer relationship management, and then accomplish the innovation of marketing management of SMEs. Marketing management requires SMEs to organize production following market, and to continuously develop new products and take new marketing strategy based on market. The purpose of the above is to promote SMEs' market competitiveness and risk-withstanding ability.

\subsection{Strengthen Profit Distribution Management}

Profit distribution management means, after confirmed total profit based on accounting system, tax is declared and paid to taxation affairs departments according to income tax law and derating tax rules, and subsequently dividend distribution method is made on regulated program, i.e. distribution method and amount of dividend among profit after tax, in order to consider both enterprise development and shareholders' benefits. Profit distribution management involves profit earning of SMEs. If the profit increases steadily, shareholders will obtain high dividend or value share. While if profit decreases continuously, shareholders might transfer equities or adjust business direction. Profit distribution management is to solve the problems of how much profit to reserve after tax and how much to grant shareholders. Reserved profit will meet the capital requirements of business development, which is beneficial to improvement of strength and competitiveness of SMEs, and prevent business risks. Therefore, scientific management of value chain for good profit is the premise of profit distribution management. On the contrary, profit distribution management can provide value chain with capital support, and then promote healthy development of every activity of value chain. Owing to weak financing ability of SMEs, reserved profit is usually selected to supply capital for enlarging business scale, but the percentage of distributing dividend is relatively small. From long-term point of view, along with internal capital accumulation and enlarging business scale of SMEs, their ability of earnings and of withstanding risks will go further, and shareholders will obtain more economic benefits too.

In short, SMEs should be guided by enterprise strategy, properly select financing channels, and raise business needed capital; scientifically demonstrate potential business field and appropriately arrange production needed resources through right investment decision; strengthen various management in order to make every activity of value chain to mutually support and coordinate, and obtain competitive advantages. By effective marketing management, they need to maintain and extend customer groups, continuously develop new products and services, continuously meet new demands, and continuously exploit new market, so as to pursue bigger space of earnings and continuously enhance and promote competitive position of SMEs.

\section{References}

Deng, Nianwu. (2008). Theory and practice of SME strategic cost management. Productivity Research. 2008 (24)

Dong, Benxin. (2004). Financial cost management of small business. China Financial and Economic Publishing House. 2004.

Duan, Qingsha. (2009). SME Cost Control. Accounting Research. 2009 (15).

Gong, Fengwei. (2010). Inspiration and comparison of Chinese and foreign high-tech enterprise financial 
management. Accounting Research. 2010 (10)

Han, Jingjing. (2009). Enterprises should implement extractive financial management from six aspects. Finance and Accounting. 2009 (24)

Ma, Yuanxing. (2008). Evolution of SMEs financial management under new economic environment. Modern Economic Research. 2008 (12)

Zhao, Ximei. (2009). Strengthening Financial Management of SMEs. Finance and Accounting. 2009 (15) 